\title{
Experimental Study on the Acoustic Emission Characteristics of Saturated Sandstone Fractures with Different Orientations
}

Gangwei Li ( $\sim$ gangweili@163.com )

Anhui University of Science and Technology https://orcid.org/0000-0002-6385-3452

\section{Yunhai Cheng}

Anhui University of Science and Technology

\section{Yifan Wang}

Shandong University of Science and Technology

\section{Fenghui Li}

Anhui University of Science and Technology

\section{Xiangqian Wang}

Anhui University of Science and Technology

\section{Tenggen Xiong}

Anhui University of Science and Technology

\section{Research Article}

Keywords: Evolutionary mechanism, Acoustic emission, Carrying capacity, Ringing count

Posted Date: April 19th, 2021

DOI: https://doi.org/10.21203/rs.3.rs-397543/v1

License: (1) This work is licensed under a Creative Commons Attribution 4.0 International License. Read Full License 


\title{
Experimental study on the acoustic emission characteristics of saturated sandstone fractures with different orientations
}

\author{
Gang-wei $\mathrm{Li}^{1}$, Yun-hai Cheng ${ }^{1,2}$, Yi-fang Wang ${ }^{2}$, Feng-hui Li $^{1\left({ }^{(}\right)}$, Xiang-Qian Wang ${ }^{1}$, Teng-gen Xiong ${ }^{1}$ \\ 1.State Key Laboratory of Deep Coal Mine Mining Response and Disaster Prevention and Control, Anhui \\ University of Science and Technology, Huainan, Anhui 232000, China \\ 2. Mining Engineering Research Institute, Shandong University of Science and Technology, Tai'an 271000, \\ China
}

\begin{abstract}
In order to investigate the mechanical characteristics of rocks under saturated water conditions, uniaxial loading experiments were conducted on rock specimens using the RMT-150B Rock Mechanics Experiment System based on theoretical analysis of the damage evolution mechanism of rock specimens considering saturation factors. And the damage of the specimens was monitored using the Soft Island DS5$16 \mathrm{~B}$ acoustic emission system. During the test, the specimens were taken from six rock samples in different directions at the same roadway section location in a coal mine. The combined findings suggest that: The dispersion rate is positively correlated with the bearing capacity of rock specimens taken from different directions, AE ringing counts, amplitude, and energy appear to have a time-limited steady increase influenced by direction. For rock specimens in the same plane, the rock damage instantaneous energy lag amplitude and $\mathrm{AE}$ activity is proportional to the direction angle. The $\mathrm{AE}$ localization points in different directions are randomly distributed and scattered in various areas, and fracture beams and surface cracks are produced inside the rock corresponding to the $\mathrm{AE}$ acoustic emission.
\end{abstract}

Key words: Evolutionary mechanism; Acoustic emission; Carrying capacity; Ringing count

\section{Introduction}

In the process of tunnel excavation, rock fracture damage process is often the microscopic manifestation of rock instability, rock joints and water-bearing fissures are the main reason for the reduction of rock strength and disorder of discontinuity and inhomogeneity of internal medium, and groundwater becomes one of the main factors affecting rock stability.

In recent years, acoustic emission statistics and mechanical characterization have been used as the main experimental method to study the extension of damage cracks within materials to fracture, and $\mathrm{AE}$ techniques have shown remarkable results. To study the acoustic emission characteristics of coal samples during deformation and damage under different stress paths(Su et al.2009). The characteristics of acoustic emission sequences during deformation and damage of granite were investigated(Jiang et al. 2000). Uniaxial compression acoustic emission tests were conducted on rocks of different lithologies to obtain the load-axial deformation curves and acoustic emission parameters during the whole process of rock rupture(Wu et al.2012). The effects of initial cohesion and internal friction angle on the damage process and acoustic emission of uniaxial plane strain compressed rock samples with random material defects were simulated by FLAC(Wang et al.2008). Triaxial compression tests on granite under different surrounding pressures and different
temperatures(Zhang et al.2014 ). To study the propagation law of acoustic emission signals of Yunnan pine specimens under different moisture content conditions( $\mathrm{Li}$ et al.2019). The damage evolution pattern and acoustic emission parameter characteristics of sandy mudstone under different loading rates were studied experimentally(Cao et al.2015). Experimental studies on the acoustic emission characteristics of sandstone during shear damage at three different water content states of $0 \%$, $50 \%$ and $100 \%$ saturation respectively were conducted in the past(Xu et al.2012). To study the mechanical properties and acoustic emission characteristics of uniaxial compression of coal rocks under different gas pressures (Gao et al.2018). Uniaxial full process loading and unloading tests on rock on a rigid press under different loading conditions.(Li et al.2010). The acoustic emission parameters of marble specimens were tested in the conventional triaxial and unloading process to investigate the difference of acoustic emission characteristics of the damage process of marble under two stress paths: loading and unloading; and to analyze the characteristics of acoustic emission and its frequency and b-value change in each stage of the deformation and damage process of marble to explore the precursor information of the damage of the rock under different surrounding pressure(Zhang et al. 2012, 2015). The acoustic emission signals under different uniaxial pressurization methods were studied, and the variation characteristics of the acoustic emission 
rate received by different channels during the whole deformation process from pressurization to damage were investigated(Zang et al.1987).

Previous studies have generally chosen advanced techniques to explore and study the process of fracture extension and evolution in various types of rocks, and to some extent reveal the damage mechanism of fractured rocks. However, the above study failed to consider the uniaxial force damage characteristics of the surrounding rock under different directions in the actual situation of the underground project. In this paper, the damage and acoustic emission characteristics of saturated sandstone in different directions are studied. Through the analysis of joint softening, acoustic emission parameters and rock crack development and localization point distribution law, it is of great significance for the analysis of the stability of surrounding rock and water content state in different directions in the same section of the roadway.

\section{Fundamentals of rock damage evolution}

According to the fiber bundle model theory [15], the rock is assumed to have $\mathrm{n}$ fibers, an external force $\mathrm{F}$ is applied and a fiber in the model breaks beyond a critical load value, and the unit strength is assigned to each fiber under the saturation factor according to the probability theory (Jiang et al.2017):

$$
P(s)=1-\mathrm{e}^{-\left[\left(\frac{s}{\phi^{\beta}}-\varepsilon\right) / \omega\right]^{\rho}}
$$

Where: $P(s)$ is the probability of a fiber unit breaking when the external load is; $\rho$ is the Weibull exponent; $\boldsymbol{\phi}$ is the fiber saturation, $0<\phi<1 ; \beta$ is the exponential factor of saturation, improve the accuracy of the saturation factor to facilitate control, $\beta>1 ; \varepsilon, w$ is the load reference coefficient, it is generally assumed that, $\varepsilon, \rho$ are 0 and 1 .

Assume that the probability of a fiber unit breaking after being subjected to loads s1 and s2:

$$
p\left(s_{1}, s_{2}\right)=\frac{P\left(s_{2}\right)-P\left(s_{1}\right)}{1-P\left(s_{1}\right)}=1-\mathrm{e}^{-\left(\left(\frac{s_{2}}{\phi^{\beta}}\right)^{\rho}-\left(\frac{s_{1}}{\phi^{\beta}}\right)^{\rho}\right)}
$$

where $P\left(\mathrm{~s}_{1}, \mathrm{~s}_{2}\right)$ represents the probability of fracture of the fiber unit under the new load of $s_{2}$ after being subjected to $s_{1}$ in the initial state. This deduces that the probability of unbroken fibers under the new load is:

$$
w\left(s_{1}, s_{2}\right)=1-p\left(s_{1}, s_{2}\right)=\mathrm{e}^{-\left(\left(\frac{s_{2}}{\phi^{\beta}}\right)^{\rho}-\left(\frac{s 1}{\phi^{\beta}}\right)^{\rho}\right)}
$$

According to the macroscopic stress instanton equation for fiber bundles, the remaining fiber size at the time of stress redistribution after fiber breakage is set to be $E_{k+1}$, and the new load $\mathrm{s}_{\mathrm{k}+1}$, which causes fiber breakage, should satisfy(Wang.2015):

$$
\sigma(s)=N E s[1-P(E s)]
$$

Where $N$ is the Young's modulus; $E$ is the fiber size; $s$ is the load applied to the fiber unit; for simplicity of calculation, $N$ is assumed to be 1 .

From equations (1) to (4), the new load of fiber breakage $\mathrm{s}_{\mathrm{k}+1}$ can be solved as follows:

$$
S_{\mathrm{k}+1}=\frac{\sigma\left(s_{k+1}\right)}{E_{k+1} \omega\left(s_{1}, s_{k}\right)}
$$

By defining the fiber size after the bad simulation of (5) as $E_{k+1}$ and defining the survival rate $Q_{k}=E_{k} / E$, the residual rate of the fiber bundle after $\mathrm{k}+1$ steps of the cycle is $Q_{k+1}=1-P\left(s_{1}, s_{k}\right)$, then the cycle equation can be constructed(Pradhan et al.2010):

$$
\begin{aligned}
& S_{k+1}=\frac{\sigma}{1-P\left(s_{1}, s_{k}\right)},\left(s_{0}=\sigma\right) \\
& E_{k+1}=1-P\left(\frac{\sigma}{E_{k}}\right),\left(E_{0}=1\right)
\end{aligned}
$$

When the fracture process of the fiber bundle model reaches equilibrium (the symbol with $\alpha$ indicates the value of the parameter in the equilibrium state of the fiber bundle model), the load and fiber size reach a constant value of:

$$
\begin{aligned}
& S_{\mathrm{k}+1}=\mathrm{S}_{\mathrm{k}}=S^{\alpha} \\
& E_{\mathrm{k}+1}=E_{\mathrm{k}}=E^{\alpha}
\end{aligned}
$$

Bringing (1), (8) and (9) into (6) and (7), it can get:

$$
\begin{gathered}
S_{\mathrm{k}}=\frac{\sigma \mathrm{g} \phi^{\beta}}{Q_{k}} \\
\sigma^{\rho}=-\frac{\left.\ln E^{\alpha} \mathrm{g} Q^{\alpha} \mathrm{g} \omega\right)^{\rho}}{\phi^{\beta \rho}} \\
\sigma=\boldsymbol{s}^{\alpha} \mathrm{e}^{-\left(\frac{\sigma \mathrm{g} \phi^{\beta}}{Q^{\alpha} \omega}\right)^{\rho}}
\end{gathered}
$$

Substituting equation (11) for the derivative and making the derivative 0 , it finds that:

$$
S^{\alpha}=\frac{\ln E^{1 / \rho} \mathrm{g} \omega}{\phi^{\beta}}
$$

Substituting equation (13) into equation (12), it can derive the ultimate stress $\alpha_{\mathrm{c}}$ :

$$
\left.\begin{array}{l}
S^{\alpha}=\frac{\ln E^{1 / \rho} \mathrm{g} \omega}{\phi^{\beta}} \\
\sigma_{c}=\frac{\ln E^{1 / \rho} \cdot \omega}{\phi^{\beta}} g^{-\left(\frac{\phi^{\beta}}{\rho}\right)}
\end{array}\right\}
$$

That is, the general calculation expression for 
the peak load is obtained.

\section{Indoor acoustic emission experiment of sandstone joints}

\subsection{Sample preparation}

The test specimen was taken from the joint development area at $472 \mathrm{~m}$ from the location of the pull gate in a centralized return air tunnel of a coal mine. The section of the roadway was selected as ZXY surface, and the axial direction of the roadway was assumed to be $\mathrm{Y}$ direction. A three-dimensional coordinate system was established and the rock was oriented and processed as shown in Figure 1, and the original rock of the roadway was taken out and oriented according to the coordinate system. First,

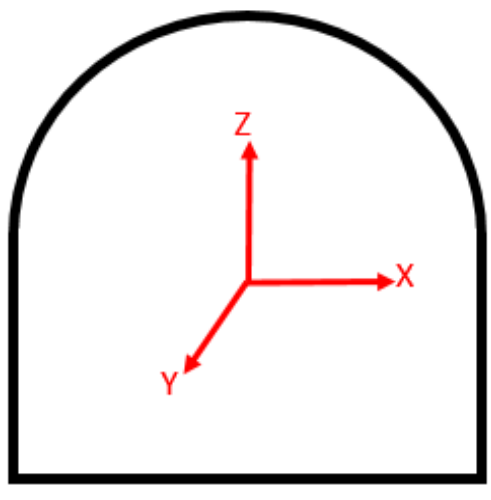

(a)

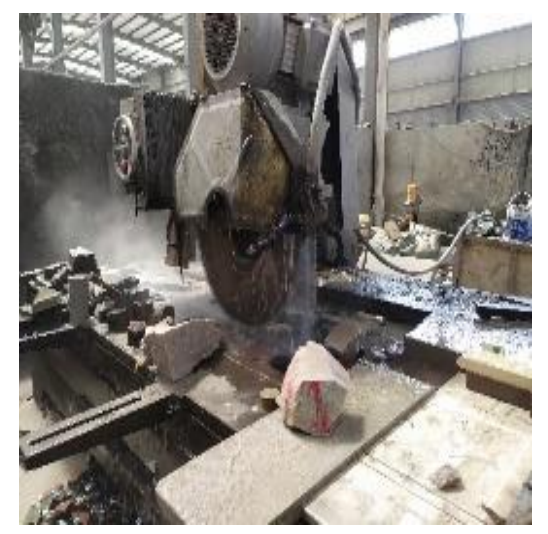

(c) the rock sample was placed on the machine processing platform and drilled into a cylinder with a $50 \mathrm{~mm}$ diameter diamond drill bit, then cut into a cylinder of $68 \sim 70.5 \mathrm{~mm}$ with a stone cutter respectively, and finally, the rock was machined into two smooth end faces of the flat plate to obtain the desired rock sample.

The accuracy testing requirements are as follows: (1) The maximum and minimum deviation of non-parallelism should be controlled within $0.07 \mathrm{~mm}$. (2) The deviation of the top and bottom diameter should not be greater than $0.4 \mathrm{~mm}$. (3) The surface of the specimen is smooth and the axial deviation is not greater than $0.25^{\circ}(\mathrm{GB} / \mathrm{T} 23561.7$. 2009).

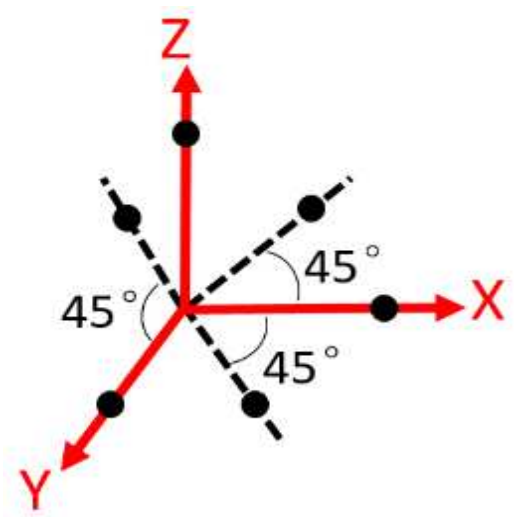

(b)

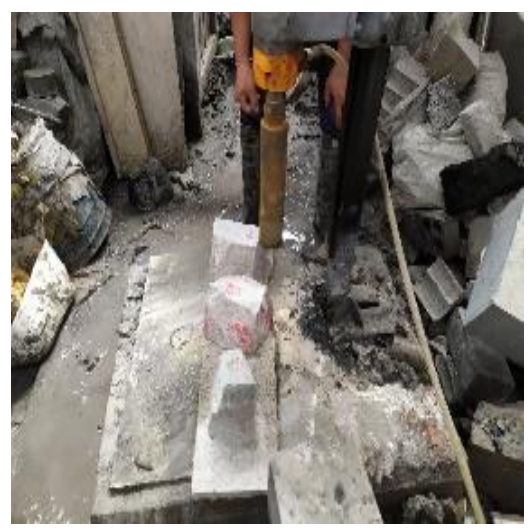

(d)

Fig. 1 Schematic diagram of specimen orientation processing. a coordinate system establishment of the roadway section, b schematic diagram of sampling direction, c rock cutting, $\mathbf{d}$ orientation turning hole

\subsection{Laboratory equipment}

The RMT-150B rock mechanics experiment system with the Soft Island DS5-16B acoustic emission system was used to conduct experiments on six directions of rock samples taken out of the laboratory, using uniaxial loading with a displacement control of $1 \mathrm{KN} / \mathrm{s}$. The acoustic emission sensor uses acoustic emission amplifier, signal filter, amplifier gain of $40 \mathrm{~dB}$, frequency range $5 \mathrm{KHz} \sim 1500 \mathrm{KHz}$, parameter interval $200 \mu \mathrm{s}$, the acoustic emission signal picked up by the sensor is further processed into acoustic emission parameters (event accumulation, event rate, ringing count, energy accumulation, etc.) by the acoustic emission instrument after pre-amplification and main amplification, and four acoustic emission are installed on the surface of the specimen probes on 
the specimen surface and spatial positioning. The BSJ-A automatic vacuum water-filling tester was used as the water-filling equipment to perform uniaxial compression splitting acoustic emission test on the rock specimens under saturated conditions.
The acoustic emission system is also equipped with shock and vibration waveform analysis and post-processing software for analyzing the main acoustic emission parameters, such as counts, amplitudes, energies and events. The rock mechanics experimental system is shown in Fig. 2.

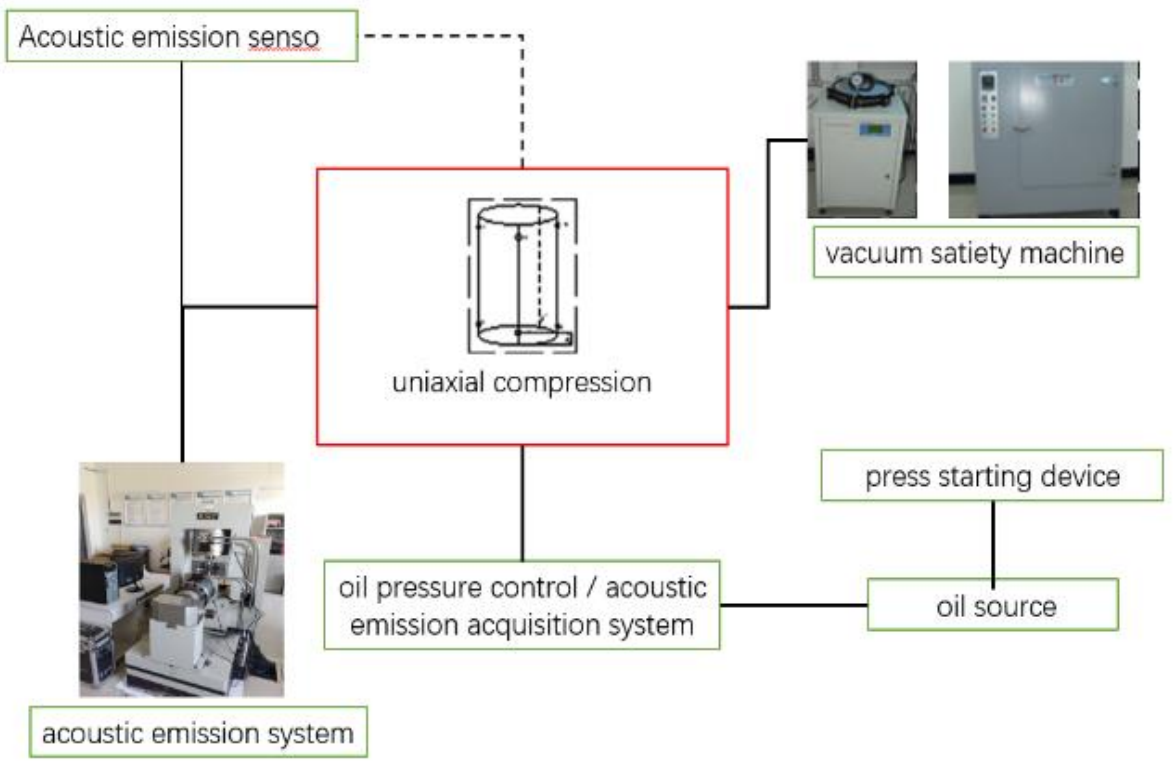

Fig. 2 Rock mechanics experimental system

\subsection{Experimental procedure}

During the test, the specimen was filled with water for 24 hours with a vacuum irrigator, and the water sample was used for uniaxial compression acoustic emission experiments, and the diameter and length were measured after inputting the information on the computer, and the feedback information was obtained by plotting the stressstrain curve during the experiment. In order to monitor the sample damage during the whole process of acoustic emission, the acoustic emission sampling frequency range was set between $1 \mathrm{kHz}$ and $1 \mathrm{MHz}$. Uniaxial compression used four acoustic emission sensors fixed to the ends of the specimen to collect signals (as shown in Figure 3). When the test equipment was installed, the surface of the fixture is evenly coated with lubricant and the contact end of the acoustic emission sensor was evenly coated with white petroleum jelly, thus reducing the experimental error caused by external factors. Set the AE threshold to $40 \mathrm{~dB}$. The compression test is continued by loading until the specimen was fractured. The sample is fixed with an elastic ring band with coupling agent, and then a positioning algorithm was applied to determine the sensor location as well as the coupling and connectivity of nearby sensors to ensure the lubrication, coupling effect and acquisition accuracy of the sensors. The uniaxial compression experiment is shown in Fig. 3.

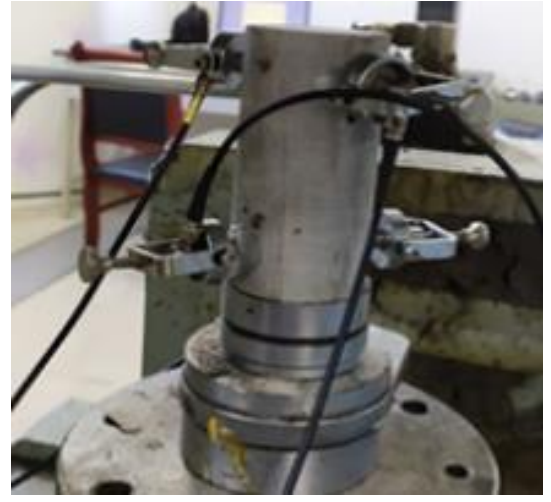

Fig. 3 Uniaxial compression AE test

\section{Analysis of experimental results}

4.1 Effect of different orientations of saturated rock on nodal softening

By analyzing the effect of stress-strain curves of fractured rocks in different directions on the softening of joints, the resultant data are shown in Figure. 4, and the uniaxial compressive strengths of sandstone columnar joints are shown in Table 1. According to the results in Table 1, the sandstone columnar joints are somewhat discrete because it has a large number of joints and fissures. The compressive strength ranges from 44.52 to 131.54 
$\mathrm{MPa}$, with an average of $96.91 \mathrm{MPa}$, and the peak load matches the actual value by theoretical calculation, and the dispersion rate of the rock sample is between $6.7 \%$ and $53.03 \%$. The large span of dispersion of saturated specimens indicates that the infiltration of water molecules through fissures into the internal minerals of the rocks reached changed the physical state of the rocks and intensified the irregularity of softening and swelling of sandstone columnar joints, leading to more complex columnar joints in mechanical properties.

Table 1 Rock parameters

\begin{tabular}{ccccccc}
\hline $\begin{array}{c}\text { Moisture } \\
\text { Status }\end{array}$ & Sample & Height(mm) & Quality(g) & Diameter(mm) & Peakload(Mpa) & Averagevalue(Mpa) \\
\hline X-axes & 70.13 & 365.34 & 50 & 44.52 \\
Y-axes & 70.26 & 354.62 & 50 & 76.60 \\
Zaturated & 70.18 & 357.25 & 50 & 88.61 \\
& X45Y(1)-axes & 62.52 & 322.74 & 50 & 129.71 & 131.54 \\
& X45Y(2)-axes & 66.96 & 343.92 & 50 & 74.52 \\
& Y45Z-axes & 95.22 & 489.98 & 50 & 103.40 \\
& Z45X(1)-axes & 100 & 512.86 & 50 & 126.38 \\
\hline
\end{tabular}

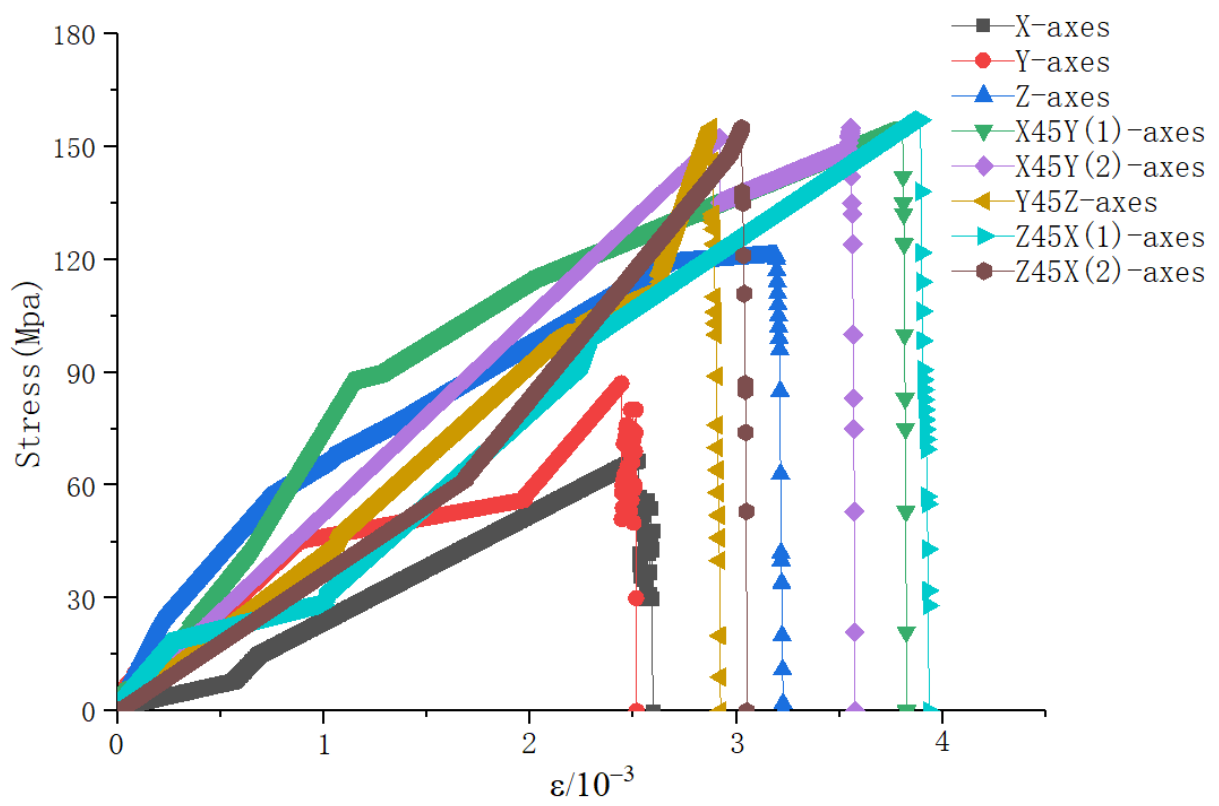

Fig. 4 Uniaxial compressive stress-strain curves of rock samples in different directions

Fig. 4 shows that the stress-strain relationship curves of the shale specimens in the saturated water condition show similar patterns. The rock sample is linear until the peak stress is reached. After the peak load is reached, a hysteresis in the stress drop of the rock sample occurs, at which time the rock sample is brittle. The horizontal direction rock samples (X- axes, Y-axes) are smaller than the vertical direction rock samples (Z-axes, X45Y(1)-axes, X45Y(2)axes, Y45Z-axes, Z45X(1)-axes and Z45X(2)-axes), and the splitting damage of rock samples has strict requirements on the peak load of stress-strain of rock samples, because X45Y(2)-axes and Z45X(2)axes rock samples dispersion rate is $1.88 \%$ and $23.7 \%$ 
higher than that of rock samples in the same direction, so the damage criteria are met in advance.

The results show that the peak load of the rock sample under the influence of water softening occurs when the damage of the rock sample agrees well with the theoretical value. If the rock sample is in vertical direction, the rock microstructure is destroyed with large porosity and fast stress-strain growth rate.

\subsection{Effect of different orientations of saturated rocks on AE parameters}

Fig. 5 shows the acoustic emission ringing

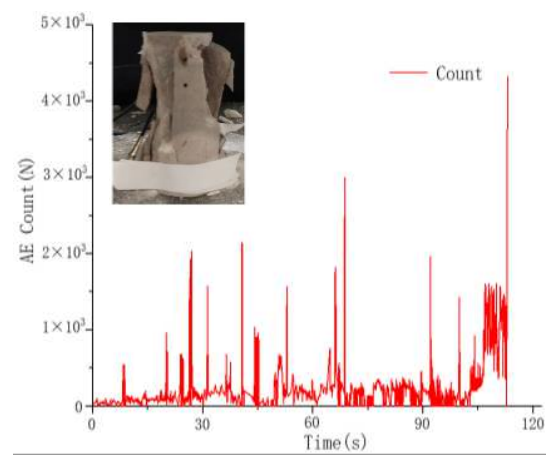

(a)

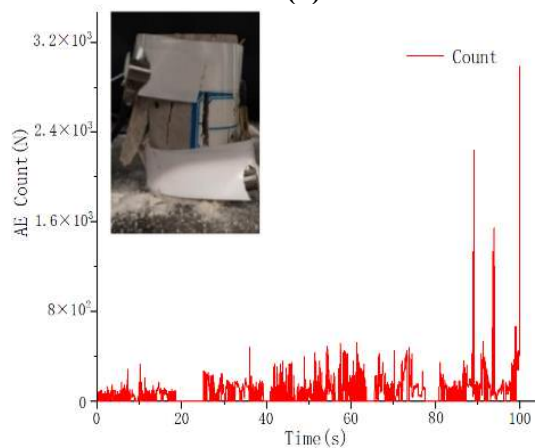

(c) count versus time variation curves of the whole process of destruction of saturated sandstone rock samples in different directions. As the rocks are affected by the loading method, bearing history, temperature, environment and other factors, the uniaxial compression numerical experiments performed under saturated conditions in different directions of the rocks show different spectra. The rock mechanics experimental system with acoustic emission system completely records the whole process of rock damage. In this paper, Z, X45Y(2), Y45Z and Z45X(2)-axes are used as examples to analyze the rock damage evolution process as Fig. 5.

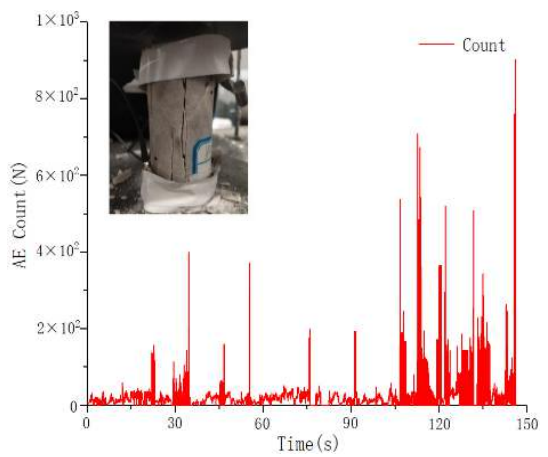

(b)

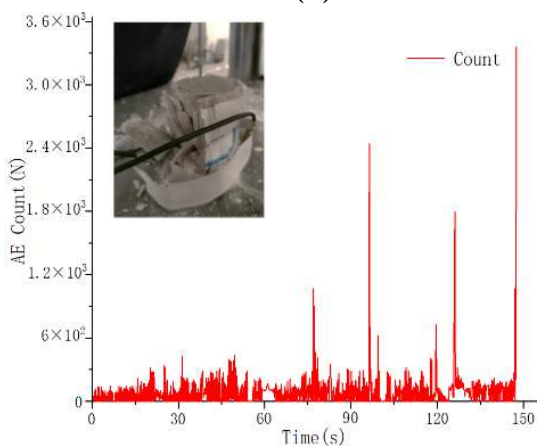

(d)

Fig. $5 \mathrm{AE}$ counts and time for rock samples with different orientations under saturated conditions. a z-axes, b x $45 \mathrm{y}(2)$-axes, $\mathbf{c}$ y45z-axes, $\mathbf{d}$ z45x(2)-axes

In the process of rock fracture accompanied by acoustic emission, the acoustic emission reflects to some extent the degree of damage to the rock itself. The amplitude-energy characteristics of the six rock samples are similar in their distribution, even though the rock samples belong to different directions, due to the non-regular characteristics of the acoustic emission signal in the reception process.

As shown in Fig. 6, there are major frequency bands in time $70 \sim 80$ s and $120 \sim 173$ s, and the rock sample in each direction is gradually compacted in the lower half of the rock under low stress, and the amplitude-energy "gap" appears in the middle as the load increases uniformly, and the low amplitudeenergy and high amplitude-energy become polarized. Fig. 6a in 0-70s amplitude intensive, each rock sample acoustic emission in the cycle of sensitive activity, the axial load suddenly increased, $\mathrm{X}$-axes amplitude instantly increased to $68 \mathrm{~dB}$, complete the destruction. With the uniform increase of axial load, the splitting damage occurred between Y-axes and Y45Z-axes in 128 138s cycles, and the difference of damage time was about $4.8 \mathrm{~s}$, and the amplitude exceeded $90 \mathrm{~dB}$. The amplitudes of the $\mathrm{Z}$ axes, X45Y(2)-axes and Z45X(2)-axes increase rapidly at high stresses, reaching $149 \mathrm{~dB}$ on average, at cycles 138 to $173 \mathrm{~s}$. The amplitudes of the Z-axes, $\mathrm{X} 45 \mathrm{Y}(2)$-axes and Z45X(2)-axes increase rapidly at high stresses, reaching $149 \mathrm{~dB}$ on average. Fig. $6 \mathrm{~b}$ shows that the acoustic emission energy will be at a low level in the low stress state, and gradually increases as the external load continues to be loaded (the rock sample absorbs energy until it is damaged), but the acoustic emission energy will continue to 
increase after it is released (e.g., at $42 \mathrm{~s}$ and $110 \sim 135$ s, as in Fig. 6b), until the rock sample is completely split and damaged.

The analysis of the above process leads to a positive linear relationship between amplitudeenergy and load of acoustic emission, and the energy release lags the amplitude during the collapse of the rock sample. The results show that at low stress, low amplitude-energy is the major part; at high stress, high amplitude-energy is the major part. During the initial loading phase, the new crack expansion leads to an increase in AE activity of the

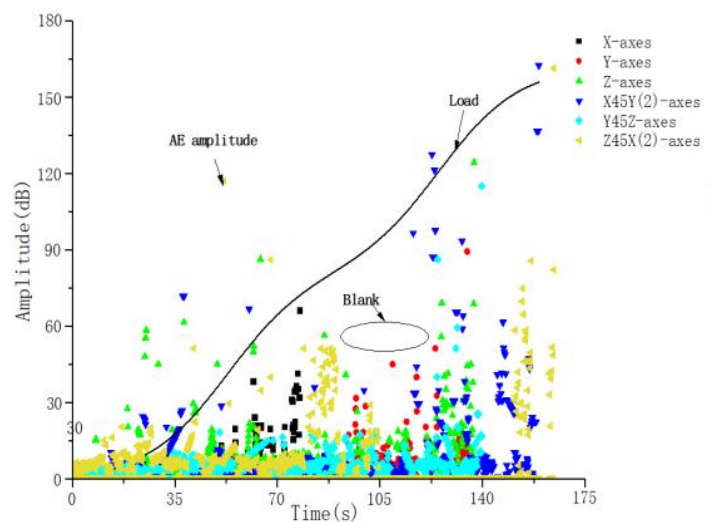

(a) specimen and a large number of low density values. When the rock sample is broken to reduce the AE activity, the rock sample accumulates strain energy in the blank phase before the sample is damaged and reaches the maximum at the moment of damage, in the form of "sudden rise - sudden decrease". In addition, Fig. 6 also shows that the rock sample source orientation affects the rock damage duration, as the orientation switches from $\mathrm{X}$-axes and $\mathrm{Y}$-axes to Z-axes, Y45Z-axes, X45Y(2)-axes and Z45X(2)axes, the faster the peak acoustic emission phase increases.

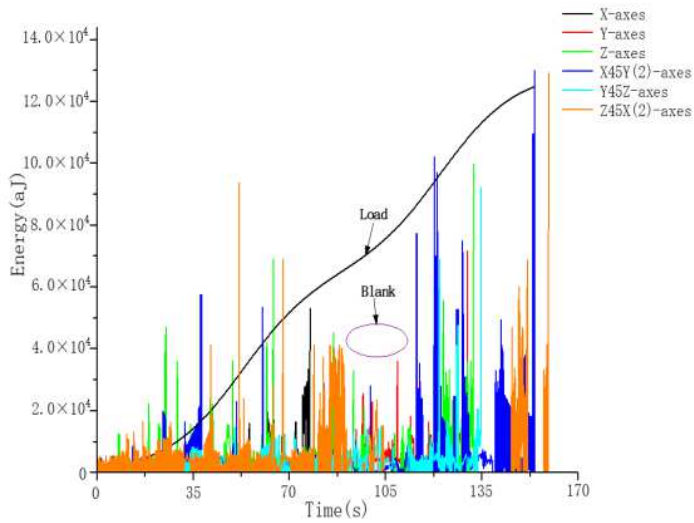

(b)

Fig. $6 \mathrm{AE}$ characteristics of rock samples with different orientations under saturation conditions. a Acoustic emission amplitude and time, $\mathbf{b}$ Acoustic emission energy and time

\subsection{Effect of different orientations of saturated rock on crack development}

In the fiber bundle model, when the fiber strength inside the rock is less than the external load, the fibers break, corresponding to microcracks in the rock. According to experiments, rock materials usually contain a large number of randomly distributed microcracks, which change the direction of stress extension under load, resulting in stress concentration at the crack tip, energy accumulation, and stress redistribution during crack expansion. Saturated sandstone columnar joint crushing conforms to three stages of uniaxial compression of rocks, i.e., crack compression dense stage, calm stage, and plastic destruction stage.

At the beginning of the experiment, the rock sample is in the compacting stage, the cracks are gradually compacted with the increasing load, and the stresses on both sides of the cracks keep converging, making the local area into a whole; after entering the calm stage, the stresses in different areas are in different directions, leading to tensile damage within the rock sample, forming some tiny new cracks and slowly expanding and penetrating, with low stored energy. When the joint crushing enters the plastic damage stage, the rock sample is further loaded, the strain energy absorbed by the tip of the new cracks increases, and when the ultimate strength of the rock is exceeded, the new cracks converge along the axial direction, and gradually form "Y" cracks as the damage depth increases. Fig. 7 shows the localization points of acoustic emission events of rock samples in different directions, each sample point represents an independent acoustic emission event, and the acoustic emission localization areas are different due to the different directions of rock samples. The X-axes, X45Y(1)axes and $\mathrm{Z} 45 \mathrm{X}(2)$-axes are concentrated in the center of the rock sample at the AE locus, while the Y-axes AE locus is also in the central part, but the number of $\mathrm{AE}$ events is less and the dispersion distance is large, and the destruction time is short. The X45Y(2)-axes AE localization points are concentrated at the upper and lower sides of the sample, and the double "Y" cracks intersect each other. Z-axes, Y45Z-axes, and Z45X(1)-axes are distributed at the lower left side of the sample, and the macroscopic cracks are developed sequentially from the bottom to the top. The results of the uniaxial acoustic emission experiments show that the overall distribution of the observed image sample points is irregular on both sides of the rock interior, and the localization points are closely connected in the high stress concentration region, and the AE localization blank area is often generated in the low stress region, which explains the complexity of the defects inside the rock. The 
rupture zone is similar for rock samples in different directions, and the $\mathrm{AE}$ locus in each area constitutes a rupture bundle, and multiple rupture bundles are connected and converge in space, and the range increases and expands in all directions to form a
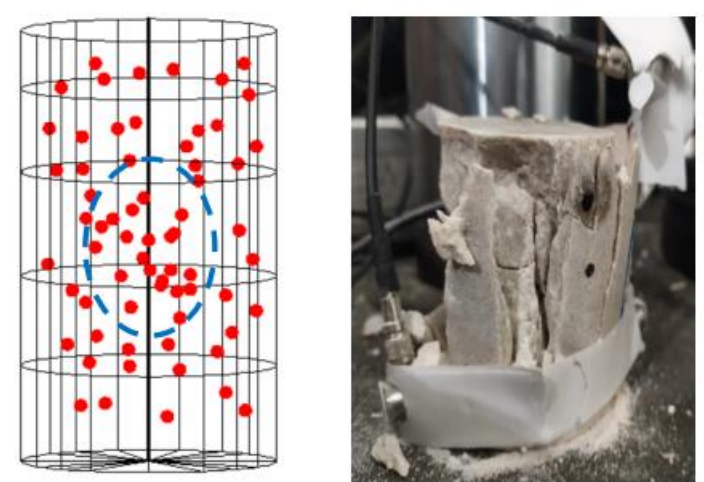

(a)
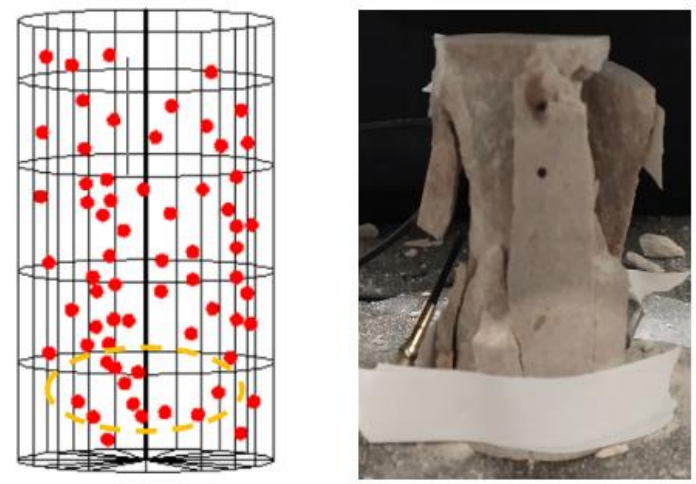

(c)
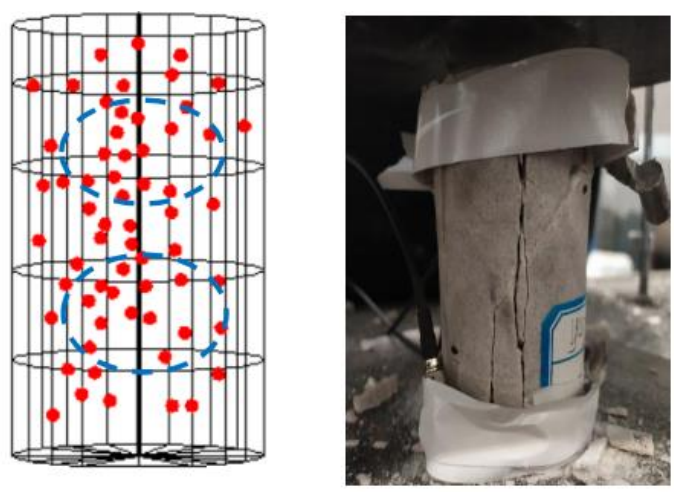

rupture zone, and then the rupture zone extends to the rock surface, and the direction is deflected to form a longitudinal cleavage crack on the surface (inside) of the rock material.
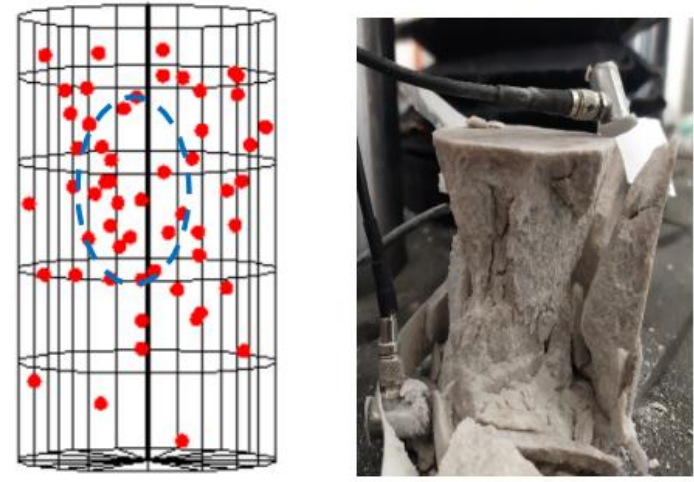

(b)
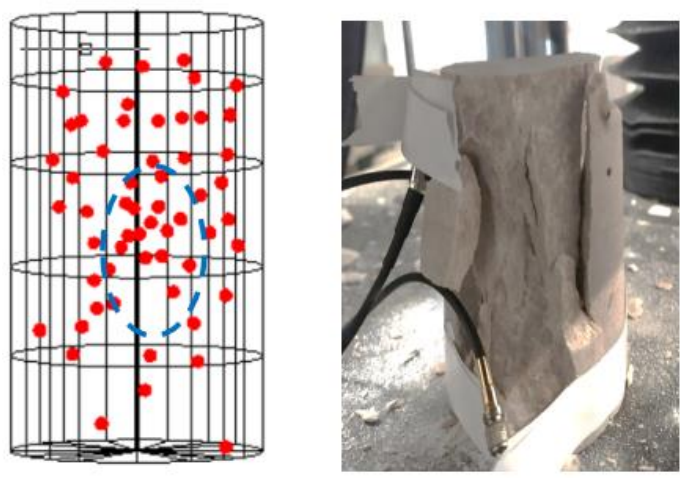

(d)
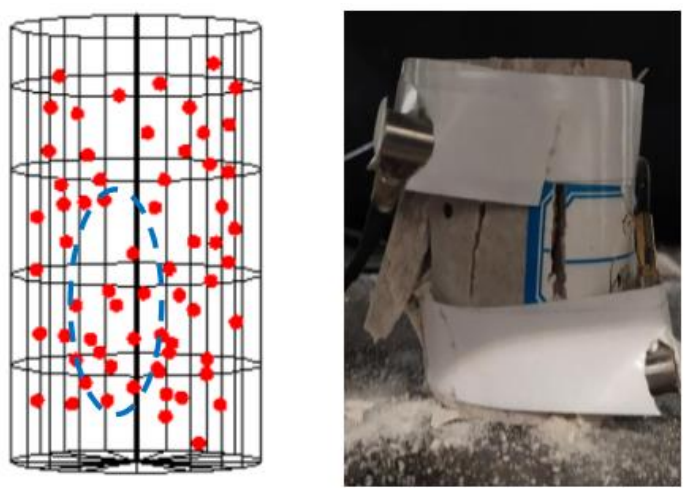

(e)

(f) 

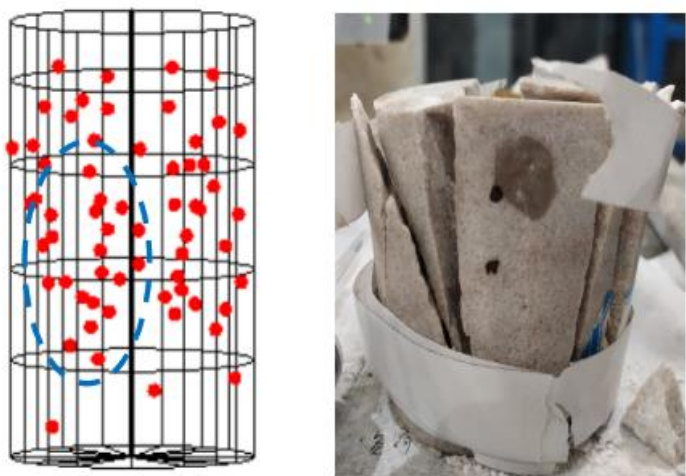

(g)
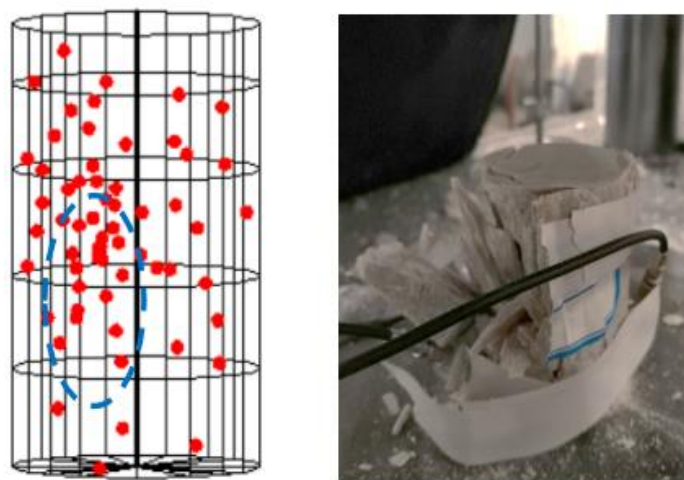

(h)

Fig. 7 Localization of acoustic emission from rocks in different directions. a X-axes. b Y-axes. c Z-axes. d x 45y(1)-axes. e x45y(2)-axes. f Y45z-axes. g Z45x(1)-axes. h Z45x(2)-axes

\section{Conclusions}

In this paper, the $\mathrm{AE}$ characteristics and damage mechanism of uniaxial compression fracture process of saturated rock samples in different directions are investigated. The analogous analysis of the acoustic emission parameters and damage process characteristics of sandstone columnar joints leads to the following conclusions: It shows that water increases the spatial irregularity of sandstone joints fractures, and the results indicate that under saturated water conditions, it increases the rock non-homogeneity and softening strength of rock joints in vertical direction is more serious.

1. Through the comparative analysis of $\mathrm{AE}$ count-amplitude - energy data, the horizontal direction $\mathrm{X}$-axis and $\mathrm{Y}$-axis $\mathrm{AE}$ count events are few and low in magnitude, the horizontal direction rock amplitude is low and the blanking period accumulates less strain energy time during the whole experiment, but the $\mathrm{AE}$ count and energy of saturated rock samples in different directions show similar trends as the load reaches the ultimate strength when released, the amplitude and energy of rock samples reach the maximum at the moment of damage, in a The amplitude and energy of the rock samples reach the maximum at the moment of damage, and are in the form of "sudden rise - sudden fall", and the energy lags behind the amplitude. Therefore, amplitude and energy can be regarded as the key conditions for rock destabilization.
2. During the uniaxial compression process, the sandstone mainly undergoes three stages, i.e., crack compacting stage, calm stage, and plastic damage stage. From the localization diagram, it can be found that the AE localization points in different directions are randomly distributed and scattered in various areas, corresponding to the destruction of the rock into broken rock pieces of different sizes, and with the increase of the destruction depth, the localization points gradually form "Y" type cracks, which induce the splitting and destruction of the rock.

\section{Data Availability}

All data used to support the findings of this study are included within the article, and there are not any restrictions on data access.

\section{Conflicts of Interest}

The authors declare no conflicts of interest.

Acknowledgement The work is supported by Innovation fund project of Anhui University of science and technology in 2020(NO. 2020CX2011)

\section{References}

[1] $\mathrm{Su} \mathrm{CD}$, Gao BB, Nan $\mathrm{H}$, et al(2009)Experimental study on the acoustic emission characteristics of deformation and damage of coal samples under different stress paths. Chinese Journal of Rock Mechanics and Engineering 28(04): 757-766.

[2] Jiang HK, Zhang L, Zhou YS(2000)Time- 
series characteristics of acoustic emission during deformation and damage of granite under different surrounding pressure conditions. Chinese Journal of Geophysics 43(6): 812-826.

[3] Wu XZ, Liu XX, Liang ZZ, et al(2012). Experimental study on the fractal characteristics of acoustic emission sequences of different rock rupture processes. Rock and Soil Mechanics 33(12): 3561-3569.

[4] Wang $\mathrm{XB}(2008)$ Numerical simulation of damage process and acoustic emission of rocks with different strength. Journal of University of Science and Technology Beijing 30(8): 837843.

[5] Zhang H, Li TB, Chen GQ, et al(2014)Acoustic emission characteristics of granite triaxial compression tests at different temperatures. Modern Tunneling Technology 51(05): 33-40.

[6] Li Y, Xu FY(2019) Characteristics of acoustic emission signals of Yunnan pine with different water content. Forestry Science 55(06): 99-105.

[7] Cao AY, Jing GC, Dou LM, et al(2015)Acoustic emission characterization of damage evolution of rock samples under different loading rates. Journal of Mining and Safety Engineering 32 (06): 57-62+69.

[8] Xu J, Wu H, Lu LF, et al(2012)Experimental study on the acoustic emission characteristics of sandstone shear under different water content. Chinese Journal of Rock Mechanics and Engineering 31(05): 55-61.

[9] Gao BB, Lv PB, Guo F(2018)Study on uniaxial compression mechanical properties and acoustic emission characteristics of coal rock under different gas pressure. Coal Science and Technology 46(01): 112-119+149.

[10] Li SL, Tang HY(2010)Acoustic emission characteristics of rock material rupture under different loading conditions. Chinese Journal of Geotechnical Engineering 32(01): 147-152.

[11] Zhang L, Wang ZQ, Shi L, et al(2012)Acoustic emission characteristics of damage processes in marble under different stress paths. Chinese Journal of Rock Mechanics and Engineering 31(06): 1230-1236.

[12] Zhang L, Ma SQ, Ren MY, et al(2015)Acoustic emission frequency and bvalue characteristics of rock damage processes under different surrounding pressures. Chinese Journal of Rock Mechanics and Engineering 34(10):2057-2063.

[13] Zang SX, Fan JL(1987)Time course and frequency characteristics of rock acoustic emission under different uniaxial pressurization methods. Acta Seismology Sinica (01): 74-88.

[14] Jiang DY, Yue HX, Zhang $X$, et al(2017)Uniaxial compression acoustic emission and fiber bundle model simulation of sandstone. Rock and Soil Mechanics 38(Supp2): 1-8.

[15] Wang L(2015)Study on the deformation stability of coal mine roadway surrounding rock based on fiber bundle model [D]. Taiyuan: Taiyuan University of Technology.

[16] PRADHAN S, HANSEN A, CHAKRABARTI B K(2010)Failure processes in elastic fiber bundles. Reviews of Modern Physics 82(1): 499-499.

[17] GB/T23561.7 (2009)Coal and Rock Physical and Mechanical Properties Determination Method, China Standard Publishing, Beijing, China.

F. $\operatorname{Li}\left({ }^{\infty}\right)$

e-mail: ahlifenghui@163.com 
Figures

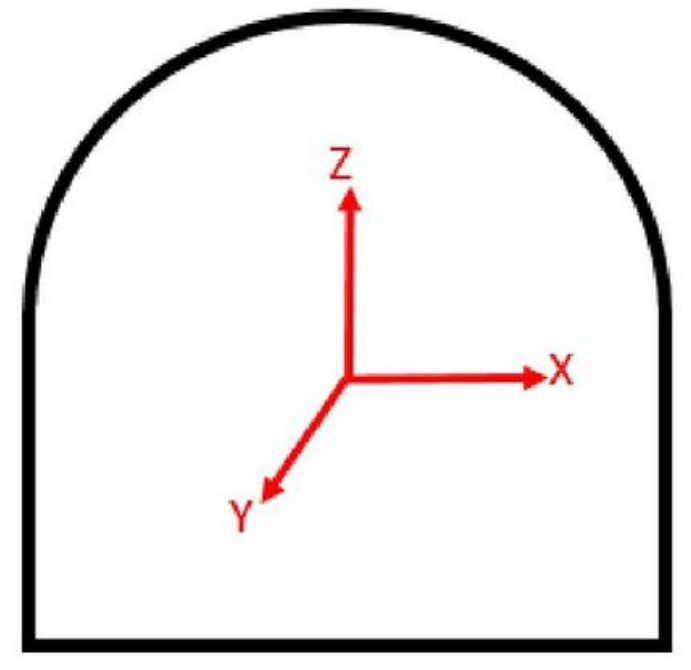

(a)

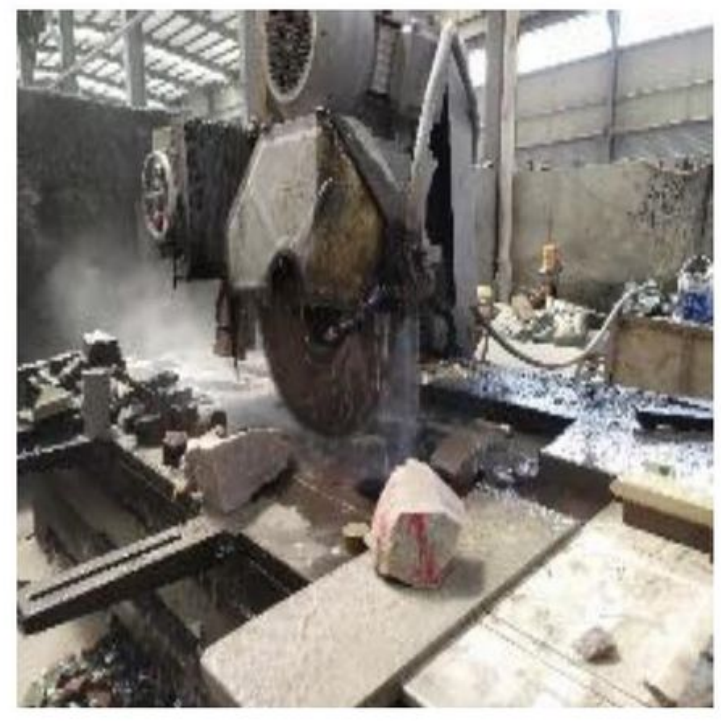

(c)

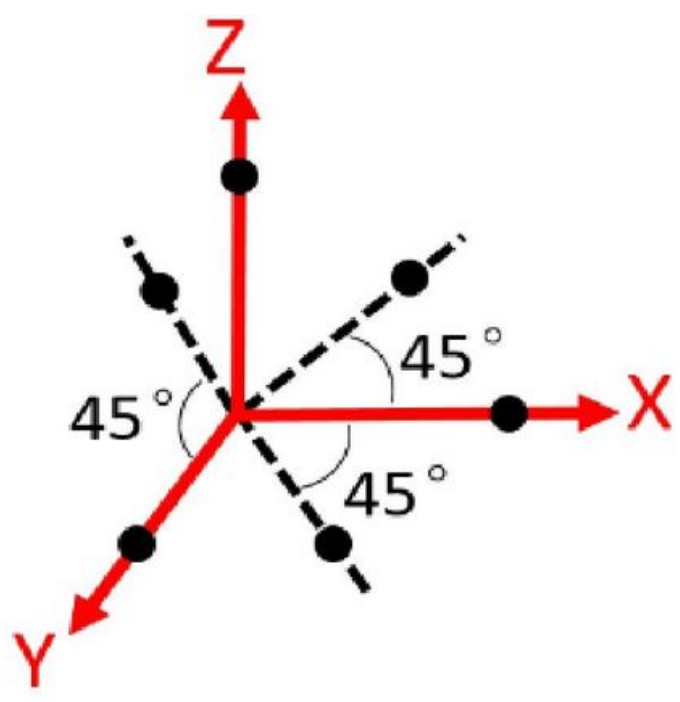

(b)

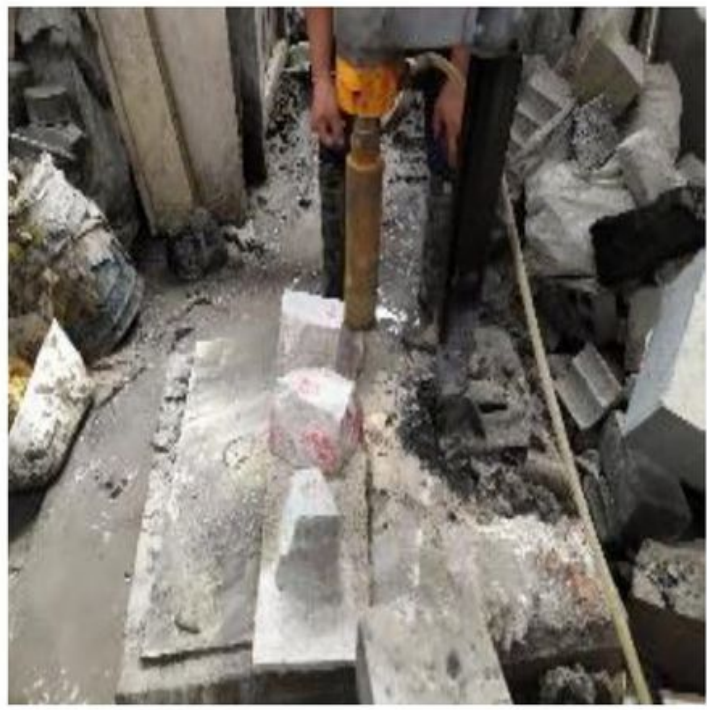

(d)

\section{Figure 1}

Schematic diagram of specimen orientation processing. a coordinate system establishment of the roadway section, b schematic diagram of sampling direction, $\mathrm{c}$ rock cutting, d orientation turning hole 


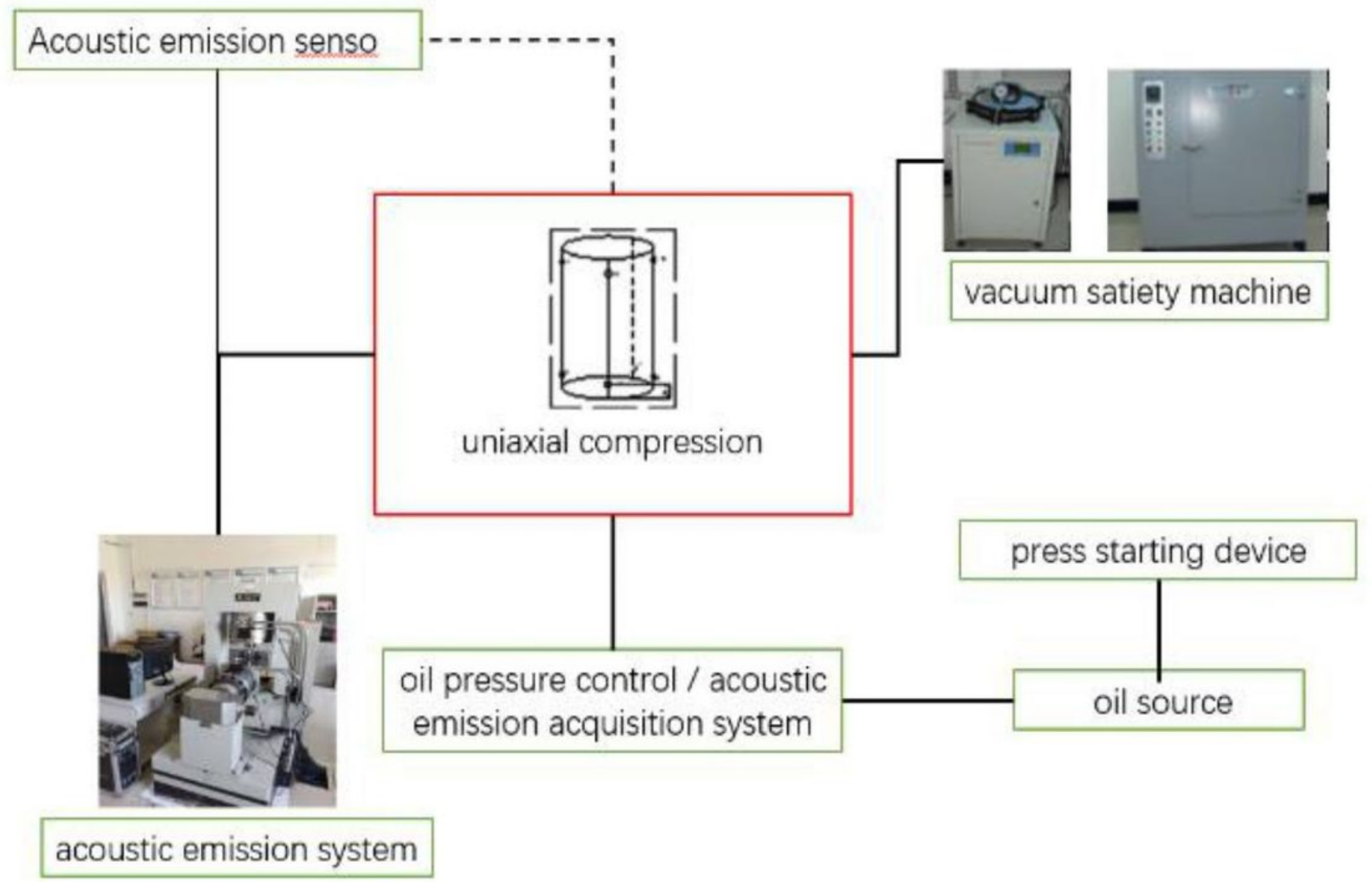

Figure 2

Rock mechanics experimental system 


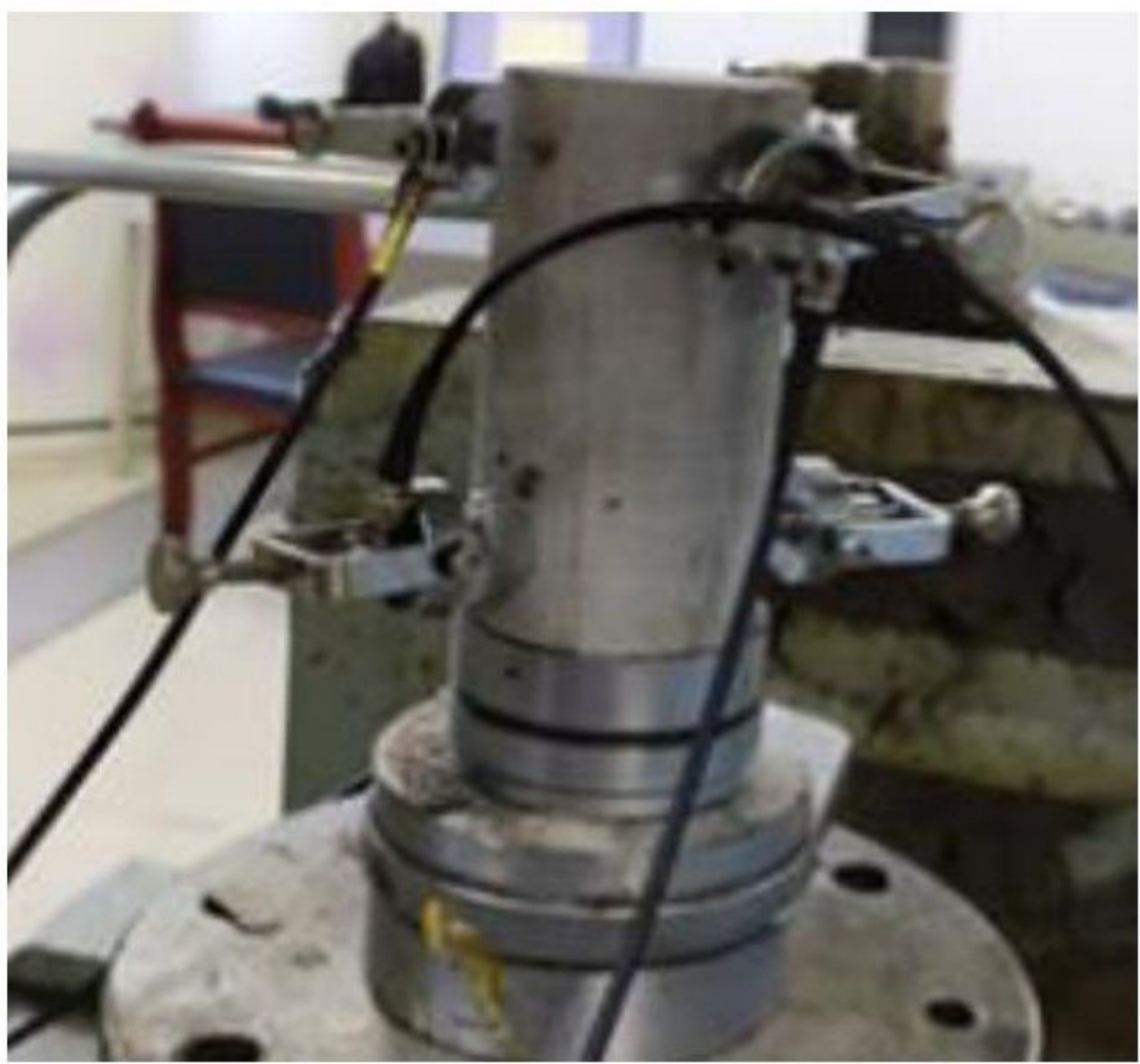

Figure 3

Uniaxial compression AE test 


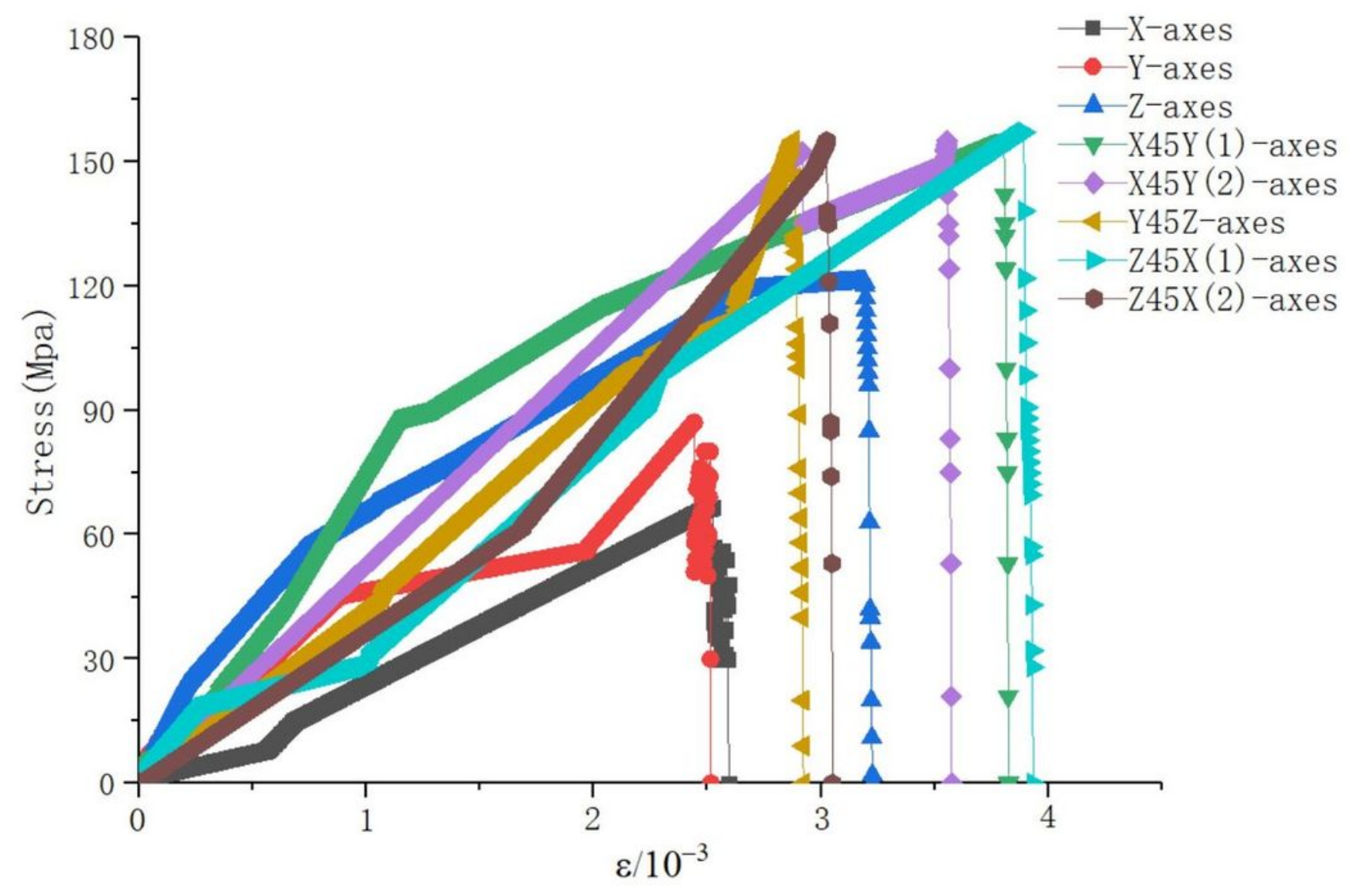

Figure 4

Uniaxial compressive stress-strain curves of rock samples in different directions 


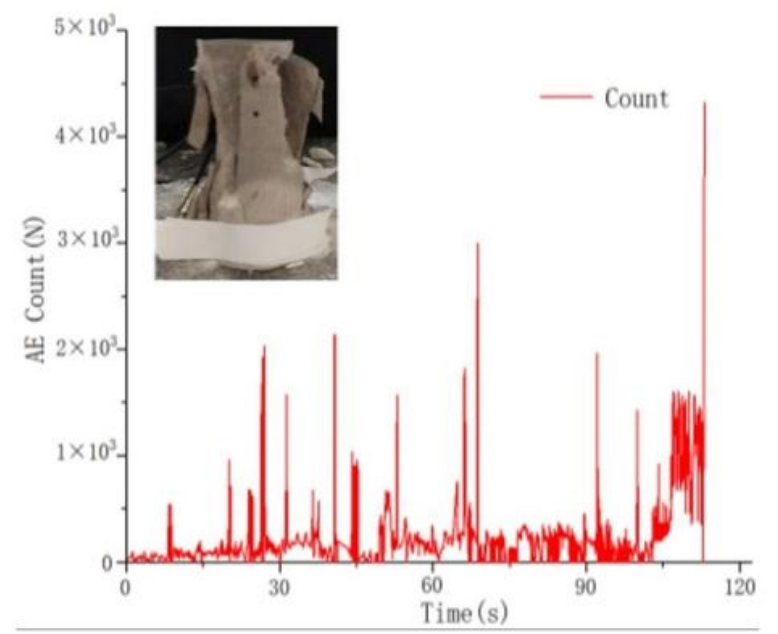

(a)

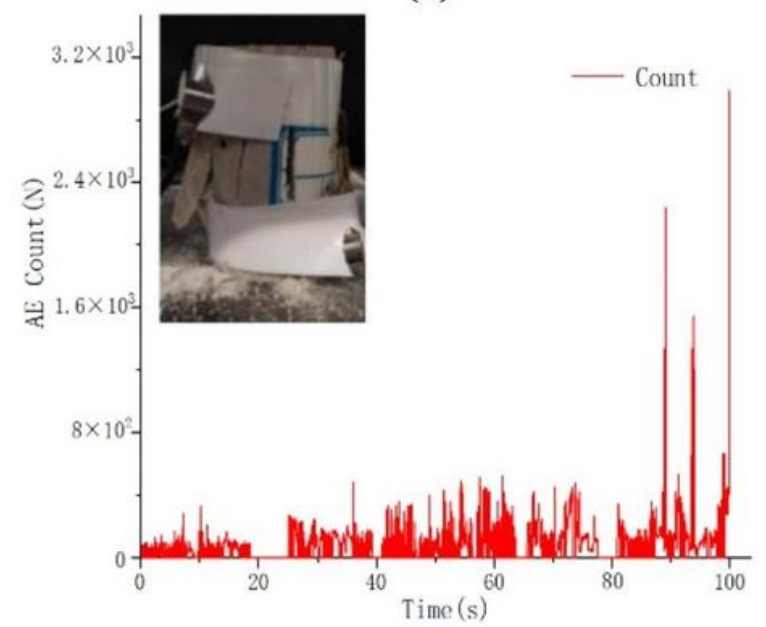

(c)

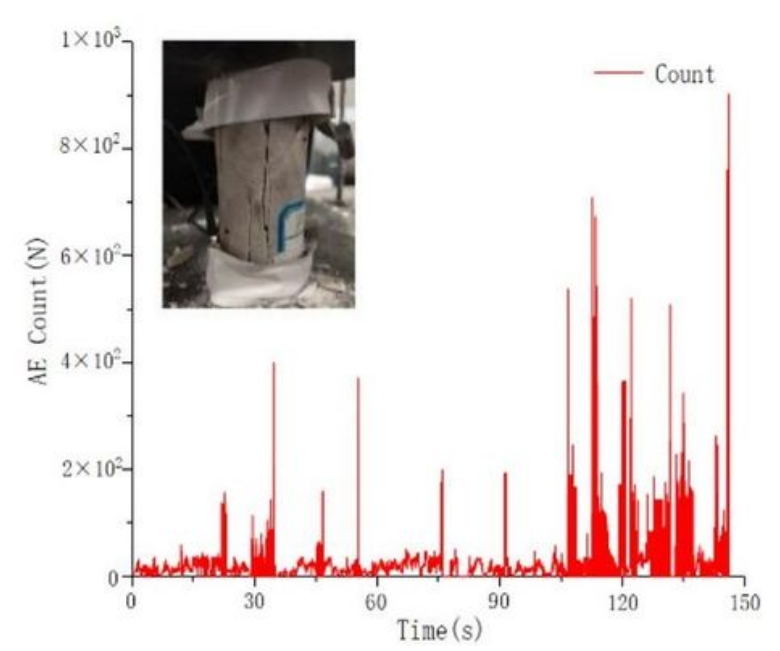

(b)

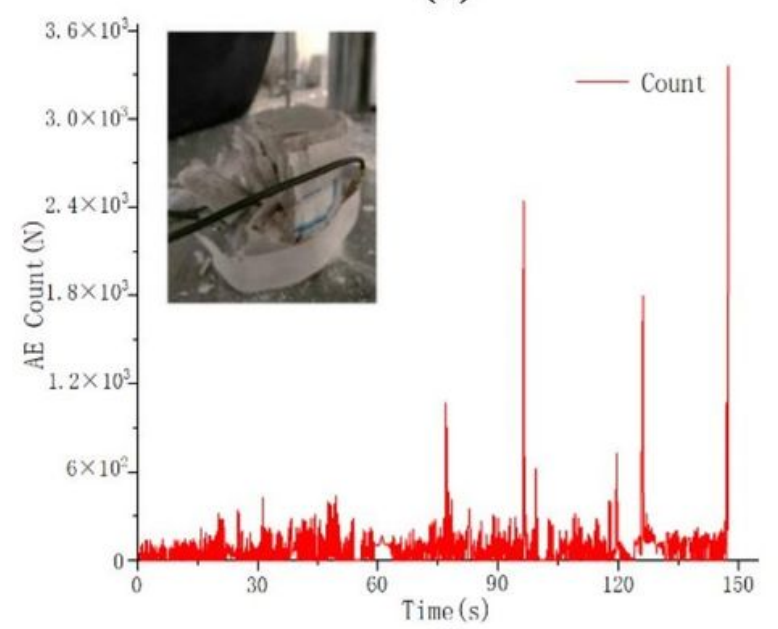

(d)

Figure 5

$\mathrm{AE}$ counts and time for rock samples with different orientations under saturated conditions. a z-axes, $b$ x45y(2)-axes, c y45z-axes, d z45x(2)-axes

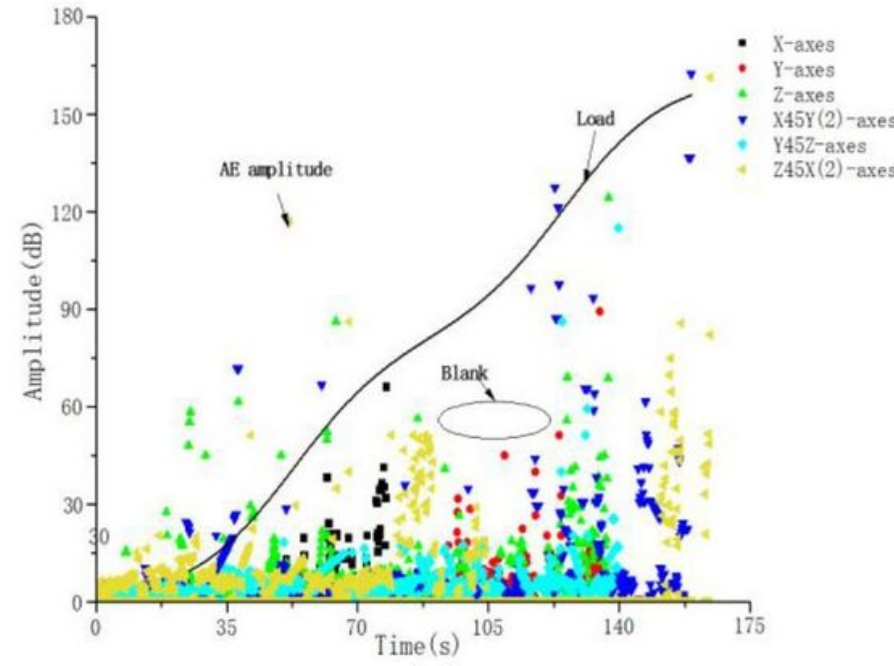

(a)

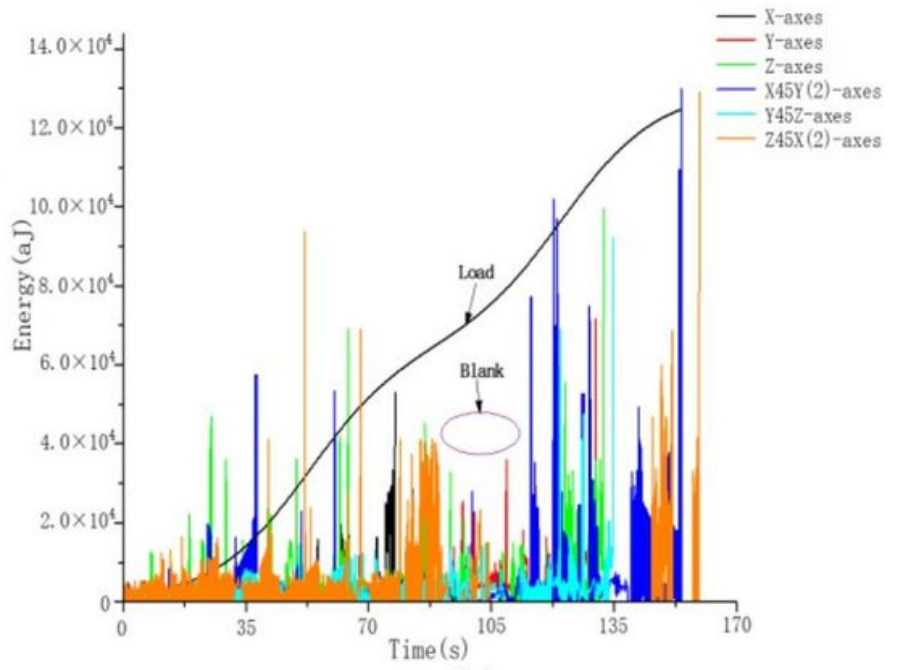

(b)

Figure 6 
AE characteristics of rock samples with different orientations under saturation conditions. a Acoustic emission amplitude and time, b Acoustic emission energy and time
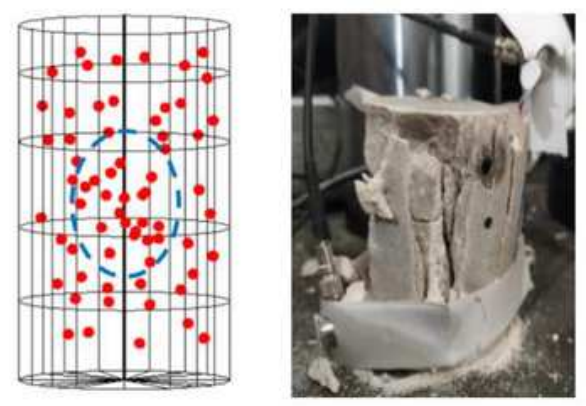

(a)
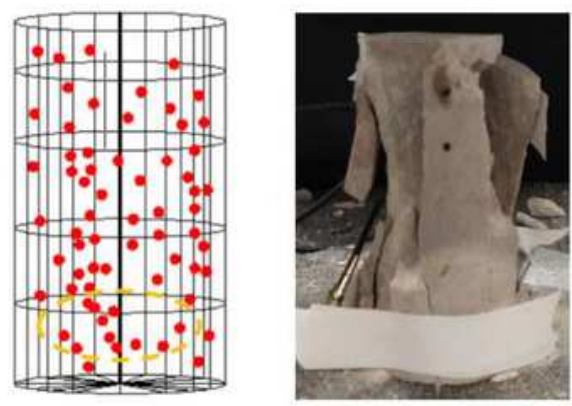

(c)
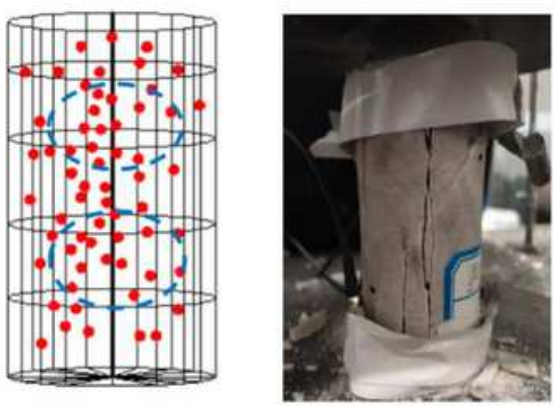

(e)
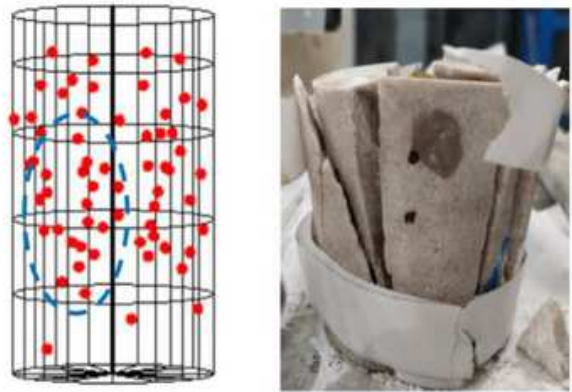

(g)
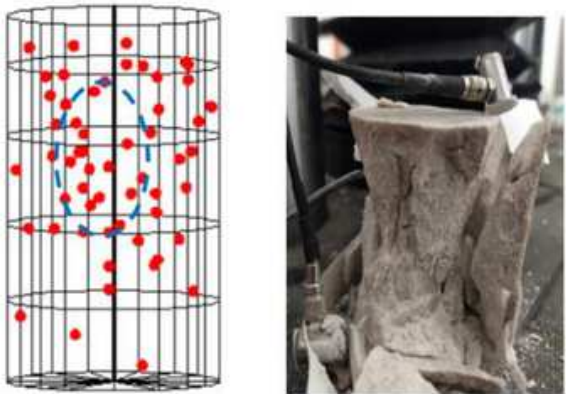

(b)
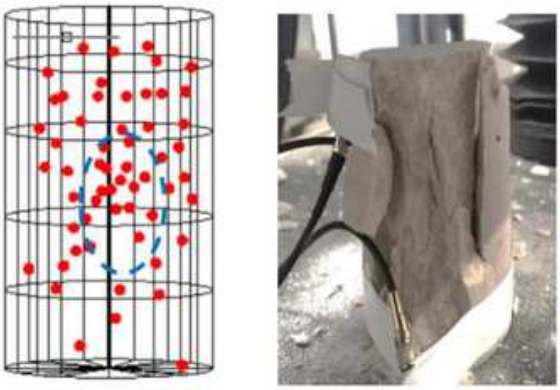

(d)
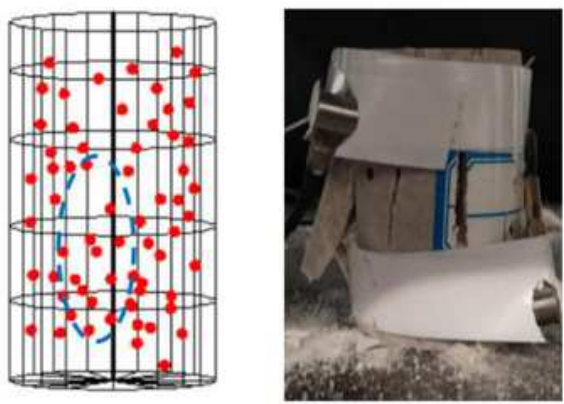

(f)
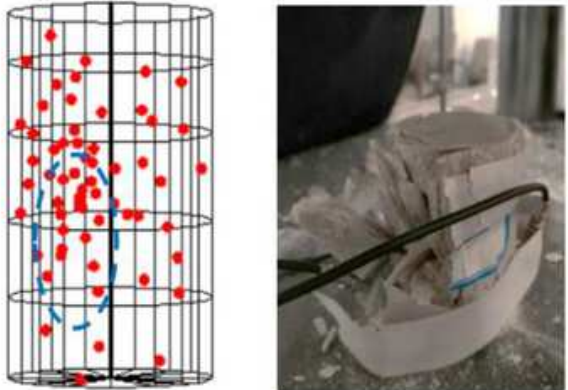

(h)

Figure 7

Localization of acoustic emission from rocks in different directions. a X-axes. b Y-axes. c Z-axes. d x45y(1)-axes. e x45y(2)-axes. f Y45z-axes. g Z45x(1)-axes. h Z45x(2)-axes 